University of Nebraska - Lincoln

DigitalCommons@University of Nebraska - Lincoln

Faculty Papers and Publications in Animal

Science

Animal Science Department

2009

\title{
Effects of Social Interactions on Empirical Responses to Selection for Average Daily Gain of Boars
}

C. Y. Chen

University of Nebraska-Lincoln

Rodger K. Johnson

University of Nebraska-Lincoln, rjohnson5@unl.edu

S. Newman

Genus - PIC NA, Hendersonville, TN

Stephen D. Kachman

University of Nebraska-Lincoln, steve.kachman@unl.edu

L. Dale Van Vleck

University of Nebraska-Lincoln, dvan-vleck1@unl.edu

Follow this and additional works at: https://digitalcommons.unl.edu/animalscifacpub

Part of the Animal Sciences Commons

Chen, C. Y.; Johnson, Rodger K.; Newman, S.; Kachman, Stephen D.; and Van Vleck, L. Dale, "Effects of Social Interactions on Empirical Responses to Selection for Average Daily Gain of Boars" (2009). Faculty Papers and Publications in Animal Science. 553.

https://digitalcommons.unl.edu/animalscifacpub/553

This Article is brought to you for free and open access by the Animal Science Department at DigitalCommons@University of Nebraska - Lincoln. It has been accepted for inclusion in Faculty Papers and Publications in Animal Science by an authorized administrator of DigitalCommons@University of Nebraska - Lincoln. 


\title{
Effects of social interactions on empirical responses to selection for average daily gain of boars
}

\author{
C. Y. Chen, * R. K. Johnson, * S. Newman, $\dagger$ S. D. Kachman, + and L. D. Van Vleck* $\oint^{1}$ \\ *Department of Animal Science, University of Nebraska, Lincoln 68583-0908; †Genus - PIC NA, Hendersonville, \\ TN 37075; $\ddagger$ Department of Statistics, University of Nebraska, Lincoln 68583-0963; \\ and $§$ Roman L. Hruska US Meat Animal Research Center, ARS-USDA, Lincoln, NE 68583-0908
}

\begin{abstract}
Effects of social interactions on responses to selection for ADG were examined with records of 9,720 boars from dam lines (1 and 2) and sire lines (3 and 4) provided by Pig Improvement Company. Each line was analyzed separately. Pens contained 15 boars. Average daily gains were measured from about 71 to $161 \mathrm{~d}$ of age and BW from 31 to $120 \mathrm{~kg}$. Models included fixed effects of contemporary groups and initial test age as a covariate and random direct genetic (a), social genetic (c), social environmental (ce), and litter (lt) effects. Estimates of direct heritability with model 1 (the full model with a, c, ce, and lt) were $0.21,0.28,0.13$, and 0.15 for lines 1 to 4 . Estimates of heritability of social effects were near zero. Estimates of total heritable variance were $55,52,38$, and $96 \%$ of phenotypic variance for lines 1 through 4 . Empirical responses to selection with model 1 were calculated us-
\end{abstract}

ing the parameter estimates from model 1. For response of 1 genetic SD for both components ( $a$ and $c$ ), the proportions of expected total gain due to social effects (with economic weights of 1 and pen size-1 = 14) were $54,28,65$, and $65 \%$ for the 4 lines. Genetic superiorities of the top $10 \%$ of boars were calculated for boars ranked using reduced models, but with EBV calculated using the full model (model 1). Average total breeding values $\left(\mathrm{ETBV}=\mathrm{EBV}_{\mathrm{a}}+14 \mathrm{EBV}_{\mathrm{c}}\right)$ for the top $10 \%$ of boars selected with model 1 were $74.08,94.26,31.79$, and $92.88 \mathrm{~g}$ for lines 1 through 4 , respectively. For rankings based on model 2 (a, ce, and lt), but EBV calculated with model 1 , average total breeding values for the top $10 \%$ were $68.15,94.03,7.33$, and $84.72 \mathrm{~g}$ with empirical correlated responses for genetic social effects from selection for direct effects of $0.93,1.89,-2.19$, and $3.52 \mathrm{~g}$ for lines 1 to 4 .

Key words: response to selection, social interaction, swine

(C)2009 American Society of Animal Science. All rights reserved.

This article is a U.S. government work, and is not subject to copyright in the United States.
J. Anim. Sci. 2009. 87:844-849 doi:10.2527/jas.2008-0937

\section{INTRODUCTION}

Current selection programs based on BLUP to predict genetic merit have the assumption of an additive genetic model with no interaction among genotypes. If genetic social effects exist, such an assumption may not be valid and could result in less than expected response to individual selection if selection is based only on direct additive genetic models (Griffing, 1967; Wright, 1986; Muir, 2005). Mixed model equations incorporating social effects were applied recently to predict genetic gains for individual selection (Muir and Schinckel, 2002). For swine selected on growth and raised in groups, competition with pen mates might affect group performance. Estimates of heritability of social effects appear to be very low in swine (Cassady

\footnotetext{
${ }^{1}$ Corresponding author: lvanvleck@unlnotes.unl.edu Received February 7, 2008.

Accepted October 27, 2008.
}

and Van Vleck, 2004; Arango et al., 2005; Chen et al., 2008) when estimated with REML. Significantly larger estimates of parameters for direct genetic effects, however, were obtained when social effects were ignored. Recently, Bijma et al. (2007) showed how social effects may contribute to total heritable variance. Instead of heritability of social effects, the ratio of total heritable variance to phenotypic variance was suggested as a measure of the importance of social effects (Bergsma et al., 2008). However, expected response to selection depends not only on the total heritable variance but also on the accuracy of the weighted index. The objective of this study was to investigate the relative importance of social effects on response for total genetic value from selection of boars for ADG.

\section{MATERIALS AND METHODS}

Animal Care and Use Committee approval was not obtained for this study because the data were obtained from an existing database. 
Table 1. Number of records and unadjusted means for ADG (g) and age on test (d) for boars

\begin{tabular}{lrrrrr}
\hline \hline Item & Line 1 & Line 2 & Line 3 & Line 4 & Total \\
\hline Records & 2,685 & 2,550 & 2,730 & 1,755 & 9,720 \\
Cn & 34 & 33 & 25 & 26 & 39 \\
Litters & 1,350 & 1,070 & 1,147 & 871 & 4,438 \\
ADG on test, g & & & & & $1,003.7$ \\
$\quad$ Mean & $1,006.1$ & 994.3 & 999.4 & $1,020.5$ & 118.9 \\
SD & 119.5 & 122.4 & 111.4 & 122.3 & 71.4 \\
Age on test, d & & & & & 5.7 \\
Mean & 71.8 & 72.3 & 70.7 & 5.8 & 160.8 \\
SD & 5.3 & 5.9 & 5.5 & & 6.9 \\
Age off test, d & 161.3 & 161.3 & 160.3 & 160.2 & 120.2 \\
Mean & 6.4 & 7.3 & 6.8 & 5.8 & 13.3 \\
SD & & & & & 122.3 \\
BW off test, $\mathrm{kg}$ & 120.3 & 120.6 & 118.4 & 13.3 & \\
Mean & 13.3 & 14.0 & 12.4 & & \\
SD & & & & & \\
\hline
\end{tabular}

${ }^{1} \mathrm{Cn}=$ contemporary groups defined as test farm-year-season.

\section{Data}

Records of 9,720 boars from dam lines (1 and 2) and sire lines (3 and 4) from Pig Improvement Company (PIC, Franklin, KY) were analyzed. Data were from 4 test farms over a 4-yr period (2000 to 2003). The area of pens for 2 test farms was $12 \mathrm{~m}^{2}$ and was $14 \mathrm{~m}^{2}$ for another 2 test farms. Boars were penned by line with 15 per pen. There were no additive relationships among lines. Average daily gain was part of the selection criteria for the 4 lines. Three to 5 sets of full sibs were in 85, 91, 86, and $93 \%$ of the pens for the 4 lines. Data were also described in a previous study (Chen et al., 2008). Number of records and unadjusted means for ADG and age on test by line are shown in Table 1 . The full pedigree file included 43,585 animals. Numbers of sires and dams that had progeny with records were 739 and 3,466 , respectively.

\section{Statistical Models and Analyses}

Previous studies indicated that including social environmental effects as permanent environmental effects in the model seems to account for most of the variation usually attributed to pen effects, because pen and social permanent environmental effects are nearly completely confounded (Van Vleck et al., 2007; Bergsma et al., 2008; Chen et al., 2008). For plants, Cappa and Cantet (2006) presented a method that might be useful to untangle the confounding among effects. In the case of animals, however, such a method would require special designs. The data structure in this study did not allow such an analysis. Thus, models in a previous study (Chen et al., 2008) were used. Models that have difficulty in separating estimates of variance components were excluded (e.g., pens as fixed effects and pens and social permanent environmental effects both included as random effects). Models with social permanent environmental effects, but not random pen effects, were chosen for this study.
Four models were compared for estimating variance components and breeding values for ADG for the 4 lines. Each model included initial age on test (day) as a covariate and fixed effects of contemporary groups (cn). Direct genetic (a), social genetic (c), social permanent environmental (ce), litter (lt), and residual effects were included in the full model as random effects. Model 1 was assumed to be the full model and was compared with reduced models 2,3 , and 4 .

The equation for model 1 was

$$
\mathrm{y}_{\mathrm{iks}}=\mathrm{cn}_{\mathrm{k}}+\mathrm{a}_{\mathrm{i}}+\sum_{\mathrm{j} \neq \mathrm{i}} \mathrm{c}_{\mathrm{j}}+\sum_{\mathrm{j} \neq \mathrm{i}} \mathrm{ce}_{\mathrm{j}}+\mathrm{lt}_{\mathrm{s}}+\mathrm{e}_{\mathrm{iks}},
$$

where $y_{\text {iks }}$ is ADG for animal i within contemporary group $\mathrm{k}$ belonging to litter $\mathrm{s} ; \mathrm{a}_{\mathrm{i}}$ is the direct additive genetic value of animal i; $\Sigma c_{j}$ and $\Sigma e_{j}$ are the sums of social (genetic and environmental) effects for 14 pen mates of animal $\mathrm{i}$; $1 \mathrm{t}_{\mathrm{s}}$ is assumed to be an independent random litter effect; and $e_{i k s}$ is assumed to be an independent random residual effect. The equations for models 2,3 , and 4 were

$$
\begin{gathered}
\mathrm{y}_{\mathrm{iks}}=\mathrm{cn}_{\mathrm{k}}+\mathrm{a}_{\mathrm{i}}+\sum_{\mathrm{j} \neq \mathrm{i}} \mathrm{ce}_{\mathrm{j}}+\mathrm{lt}_{\mathrm{s}}+\mathrm{e}_{\mathrm{iks}} \text { for model } 2, \\
\mathrm{y}_{\mathrm{iks}}=\mathrm{cn}_{\mathrm{k}}+\mathrm{a}_{\mathrm{i}}+\sum_{\mathrm{j} \neq \mathrm{i}} \mathrm{c}_{\mathrm{j}}+\mathrm{lt}_{\mathrm{s}}+\mathrm{e}_{\mathrm{iks}} \text { for model } 3, \text { and } \\
\mathrm{y}_{\mathrm{iks}}=\mathrm{cn}_{\mathrm{k}}+\mathrm{a}_{\mathrm{i}}+\mathrm{lt}_{\mathrm{s}}+\mathrm{e}_{\mathrm{iks}} \text { for model } 4 .
\end{gathered}
$$

Random effects for model 1 are assumed to be from a $\mathrm{N}(0, \mathrm{~V})$ distribution where

$$
V=\operatorname{Var}\left[\begin{array}{l}
a \\
c \\
c e \\
l t \\
e
\end{array}\right]=\left[\begin{array}{ccccc}
A \sigma_{a}^{2} & A \sigma_{a c} & 0 & 0 & 0 \\
A \sigma_{a c} & A \sigma_{c}^{2} & 0 & 0 & 0 \\
0 & 0 & I_{n} \sigma_{c e}^{2} & 0 & 0 \\
0 & 0 & 0 & \mathrm{I}_{s} \sigma_{l t}^{2} & 0 \\
0 & 0 & 0 & 0 & I_{n} \sigma_{e}^{2}
\end{array}\right]
$$


with $a$, the vector of random direct genetic effects augmented for all animals in the pedigree; $c$, the vector of random social genetic effects augmented for all animals in the pedigree; $c e$, the vector of random social permanent environmental effects for animals with records; $l t$, the vector of random litter effects; and $e$, the vector of random residual effects. The augmented numerator relationship matrix among all animals is $A, I_{n}$ is an identity matrix with order of the number of records $(n)$, and $I_{s}$ is an identity matrix with order of the number of litter(s). The direct genetic variance is $\sigma_{a}^{2}, \quad \sigma_{c}^{2}$ is the social genetic variance, $\sigma_{a c}$ is the genetic covariance between direct and social effects, $\sigma_{c e}^{2}$ is the social permanent environmental variance, $\sigma_{l t}^{2}$ is the random litter variance, and $\sigma_{e}^{2}$ is the residual variance.

Estimates of variance components were obtained with a single trait animal model using the MTDFREML programs (Boldman et al., 1995) modified for including social effects (Van Vleck and Cassady, 2004; Van Vleck et al., 2007). The program does not allow the covariance between environmental social and residual effects $\left(\sigma_{c e, e}\right)$ to be other than zero. Due to different additive relationships within pen for different pens, for this study the phenotypic variance for the full model with relationships among competitors ignored was computed as

$$
\sigma_{p}^{2}=\sigma_{a}^{2}+14 \sigma_{c}^{2}+14 \sigma_{c e}^{2}+\sigma_{l t}^{2}+\sigma_{e}^{2} .
$$

Estimates of direct and social breeding values were calculated separately for each line with model 1 for each animal with records in the line. With number of competitors of 14 , the total breeding value $\left(\mathbf{T B V}_{\mathbf{i}}\right)$ to account for heritable social effects is $T B V_{i}=a_{i}+14 c_{i}$, where $a_{i}$ and $c_{i}$ are direct and social genetic values. Bijma et al. (2007) indicated that variance of TBV represents the potential to respond to selection among individuals with $\sigma_{T B V}^{2}=\sigma_{a}^{2}+2 \times 14 \sigma_{a c}+14^{2} \sigma_{c}^{2}$. The ratio of $\sigma_{T B V}^{2} / \sigma_{p}^{2}$, which may exceed 1 , instead of heritability of social effects, would indicate the contribution of social effects to the total heritable variance as compared with the usual definition of heritability (Bergsma et al., 2008). Estimates of $\sigma_{T B V}^{2} / \sigma_{p}^{2}$ were calculated in this study. However, $\sigma_{T B V}^{2}$ represents only the variance of true values. With the weighted selection index, expected response would be proportional to the SD of the index $\left(\sigma_{I}\right)$ with $\sigma_{I}^{2}$ equal to the variance of total estimated breeding values (ETBV).

Empirical responses to selection with the different models were based on estimates of TBV. For individual $i$, the optimum weighted selection criterion $\left(\boldsymbol{I}_{\boldsymbol{i}}\right)$ for $T B V_{i}$ is $I_{i}=\hat{a}_{i}+14 \hat{c}_{i}$, where $\hat{a}_{i}$ and $\hat{c}_{i}$ are predicted direct and social genetic values weighted by economic weights of 1 and number of competitors (14) in a pen, respectively (Muir, 2005). Thus, the total response to selection $(\triangle T B V)$ per generation would be $\Delta T B V=\Delta a+14 \Delta c$, where $\Delta a$ is response for direct breeding values and $\Delta c$ is response for social breeding values (Muir, 2005; Bijma et al., 2007; Van Vleck et al., 2007).

Total estimated breeding values for ADG were calculated for each boar with each model to determine ranking within lines. Ranks of boars between models were compared using Spearman's rank correlation. Estimates of correlations of breeding values of boars calculated with different models were compared using Pearson product moment correlations with the CORR procedure (SAS Inst. Inc., Cary, NC). Genetic superiorities (empirical responses to selection) for TBV of the top $10 \%$ of boars were calculated with rankings based on reduced models, but with estimated breeding values calculated with model 1 (full model). Another approach would have been to calculate accuracy of ETBV, which is proportional to expected response to selection. One difficulty is that accuracies will be somewhat different for each animal, although an average accuracy might be used. A greater difficulty is that computing accuracy for the reduced models is a function of the true model (Henderson, 1975).

\section{RESULTS AND DISCUSSION}

\section{Estimates of Genetic Parameters}

Estimates of (co)variances and genetic parameters for ADG with the 4 models for the 4 lines are in Tables 2 and 3 . Analyses using subsets by line had similar patterns for estimates of variance components as with the same models described in the previous study (Chen et al., 2008). Differences in estimates of variance components with various models for each line might be due to sampling or to real differences among the lines (e.g., estimates of direct heritability for the sire lines were about $60 \%$ of those for the dam lines).

With model 1 (a, c, ce, and lt), estimates of direct heritability were $0.21,0.28,0.13$, and 0.15 for lines 1 through 4, respectively. Estimates of heritability of social effects were near zero and ranged from 0.000 to 0.003 for the 4 lines. Estimates of the genetic correlation between direct and social effects $\left(\mathrm{r}_{\mathrm{ac}}\right)$ were variable $(-0.37$ to 0.74$)$, but were based on very small estimates of $\sigma_{c}^{2}$. The estimate of the genetic correlation between direct and social effects could not be estimated for line 2 , because the estimate of heritability of social effects was zero. The proportion of estimated litter variance of the phenotypic variance with model 1 did not vary much by line $(0.08,0.08,0.09$, and 0.07 for lines 1 to 4 , respectively). Estimates of $\sigma_{T B V}^{2}$ were $7,475,7,527$, 4286, and 14,082 with model 1 for lines 1 through 4, respectively. The ratios of $\sigma_{T B V}^{2} / \sigma_{p}^{2}$ were $0.55,0.52$, 0.38 , and 0.96 for lines 1 through 4 , with variance due 
Table 2. Estimates of (co)variance components and genetic parameters ${ }^{1}$ for ADG (g) for boars from 2 dam lines

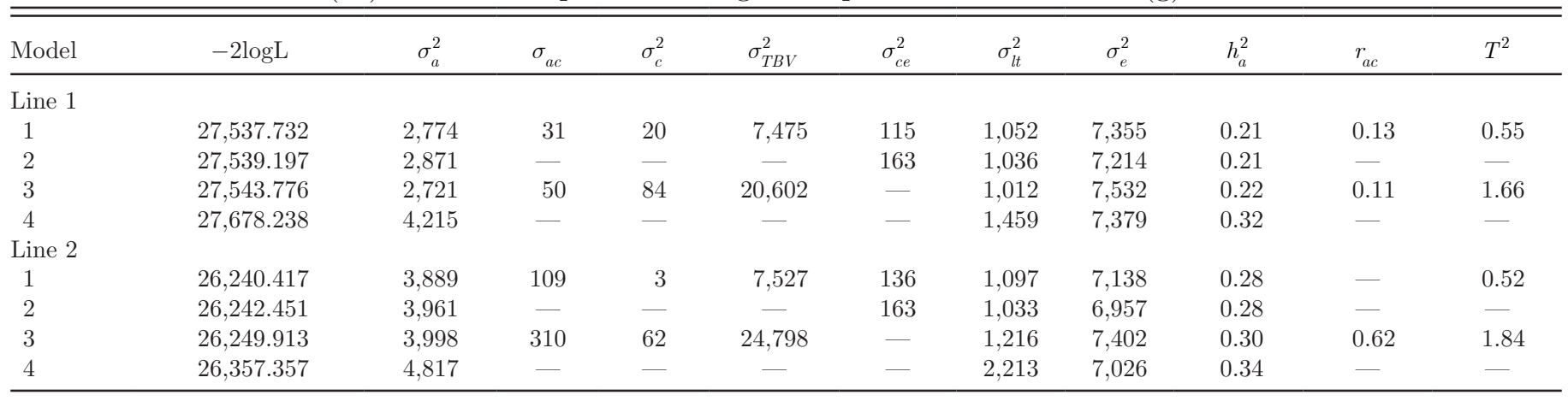

${ }^{1}$ Definitions: $\sigma_{a}^{2}=$ the direct genetic variance; $\sigma_{c}^{2}=$ the social genetic variance; $\sigma_{a c}=$ the genetic covariance between direct and social effects; $\sigma_{c e}^{2}=$ the social permanent environmental variance; $\sigma_{l t}^{2}=$ the random litter variance; and $\sigma_{e}^{2}=$ the residual variance. $\sigma_{T B V}^{2}=$ the variance of total breeding value defined as $\sigma_{a}^{2}+(2 \times 14) \sigma_{a c}+14^{2} \sigma_{c}^{2}$ (models 1 and 3 ). $h_{a}^{2}=\sigma_{a}^{2} / \sigma_{p}^{2}$, with $\sigma_{p}^{2}=\sigma_{a}^{2}+14 \sigma_{c}^{2}+14 \sigma_{c e}^{2}+\sigma_{l t}^{2}+\sigma_{e}^{2}(\operatorname{model} 1)$ or $\sigma_{p}^{2}=\sigma_{a}^{2}+14 \sigma_{c e}^{2}+\sigma_{l t}^{2}+\sigma_{e}^{2} \quad($ model 2$)$ or $\quad \sigma_{p}^{2}=\sigma_{a}^{2}+14 \sigma_{c}^{2}+\sigma_{l t}^{2}+\sigma_{e}^{2} \quad(\operatorname{model} 3)$ or $\quad \sigma_{p}^{2}=\sigma_{a}^{2}+\sigma_{l t}^{2}+\sigma_{e}^{2} \quad($ model 4$)$. $r_{a c}=\sigma_{a c} /\left(\sigma_{a} \times \sigma_{c}\right)$. $T^{2}=\sigma_{T B V}^{2} / \sigma_{p}^{2}$

to social effects contributing $63,48,68$, and $86 \%$ of $\sigma_{T B V}^{2}$. With data of domestic pigs, Bergsma et al. (2008) reported the ratio of $\sigma_{T B V}^{2} / \sigma_{p}^{2}$ to be $70 \%$ for growth rate.

Model 2 (a, ce, and lt) seemed to overestimate variances of social permanent environmental effects (163, 163, 181, and 215 for lines 1 to 4) compared with model 1 (115, 136, 147, and 102 for lines 1 to 4) probably due to capture of social genetic variance. Estimates of heritability for direct genetic effects with model 3 (no ce) for lines 1 to $3(0.22,0.30$, and 0.14$)$ were significantly different $(P<0.05)$ from estimates with model 1. Estimates of $\sigma_{T B V}^{2}$ dramatically increased compared with model 1 (20,602, 24,798, 25,431, and 26,103 for lines 1 to 4$)$. This model resulted in greater estimates of $\sigma_{T B V}^{2} / \sigma_{p}^{2}$, which ranged from 1.66 to 2.43 . For the usual model including only direct genetic, litter, and residual effects (model 4), estimates of $\sigma_{a}^{2}$ and $\sigma_{l t}^{2}$ increased compared with model 1 for the 4 lines with di- rect heritability apparently inflated for lines 1, 2, and 4.

Overall, variation due to social effects was relatively small, but with large total heritable variance for the 4 lines. Ignoring social permanent environmental effects seems to result in overestimates of variance for social genetic effects for all 4 lines. Similarly, overestimation of heritability for direct genetic effects was also apparent if the model excluded social (genetic and environmental) effects.

\section{Empirical Responses to Selection and Ranking on $E B V$}

Empirical responses to selection were calculated with model 1 under the assumption that estimates of parameters from model 1 for each line were true values. For response of 1 genetic SD for both components (a and c), the proportions of expected total gain due to social effects (with economic weights of 1 and pen size- $1=$ 14) were $54,28,65$, and $65 \%$ for the 4 lines with model 1. These calculations, however, depend on gain of 1

Table 3. Estimates of (co)variance components and genetic parameters ${ }^{1}$ for ADG (g) for boars from 2 sire lines

\begin{tabular}{|c|c|c|c|c|c|c|c|c|c|c|c|}
\hline \multicolumn{12}{|l|}{ Line 3} \\
\hline 1 & $27,479.256$ & 1,381 & -67 & 24 & 4,286 & 147 & 1,017 & 6,150 & 0.13 & -0.37 & 0.38 \\
\hline 3 & $27,492.195$ & 1,485 & 41 & 116 & 25,431 & - & 1,013 & 6,328 & 0.14 & 0.10 & 2.43 \\
\hline 4 & $27,730.800$ & 1,544 & - & - & - & - & 2,230 & 7,101 & 0.14 & - & - \\
\hline \multicolumn{12}{|l|}{ Line 4} \\
\hline 3 & $18,008.032$ & 1,973 & 274 & 84 & 26,103 & - & 1,106 & 8,477 & 0.15 & 0.67 & 2.05 \\
\hline 4 & $18,126.370$ & 4,281 & - & - & - & - & 1,899 & 7,407 & 0.32 & - & - \\
\hline
\end{tabular}

${ }^{1}$ Definitions: $\sigma_{a}^{2}=$ the direct genetic variance; $\sigma_{c}^{2}=$ the social genetic variance; $\sigma_{a c}=$ the genetic covariance between direct and social effects; $\sigma_{c e}^{2}=$ the social permanent environmental variance; $\sigma_{l t}^{2}=$ the random litter variance; and $\sigma_{e}^{2}=$ the residual variance. $\sigma_{T B V}^{2}=$ the variance of total breeding value defined as $\sigma_{a}^{2}+(2 \times 14) \sigma_{a c}+14^{2} \sigma_{c}^{2}$ (models 1 and 3 ). $h_{a}^{2}=\sigma_{a}^{2} / \sigma_{p}^{2}$, with $\sigma_{p}^{2}=\sigma_{a}^{2}+14 \sigma_{c}^{2}+14 \sigma_{c e}^{2}+\sigma_{l t}^{2}+\sigma_{e}^{2}(\operatorname{model} 1)$ or $\sigma_{p}^{2}=\sigma_{a}^{2}+14 \sigma_{c e}^{2}+\sigma_{l t}^{2}+\sigma_{e}^{2} \quad($ model 2$)$ or $\quad \sigma_{p}^{2}=\sigma_{a}^{2}+14 \sigma_{c}^{2}+\sigma_{l t}^{2}+\sigma_{e}^{2} \quad(\operatorname{model} 3)$ or $\quad \sigma_{p}^{2}=\sigma_{a}^{2}+\sigma_{l t}^{2}+\sigma_{e}^{2} \quad(\operatorname{model} 4)$. $r_{a c}=\sigma_{a c} /\left(\sigma_{a} \times \sigma_{c}\right)$. $T^{2}=\sigma_{T B V}^{2} / \sigma_{p}^{2}$ 
Table 4. Average estimates of direct genetic, competition genetic, and total breeding values $(\mathrm{ETBV})^{1}$ for $\mathrm{ADG}(\mathrm{g})^{2}$ for the top $10 \%$ of boars ranked based on each model, but with EBV calculated with model 1 for 2 dam lines

\begin{tabular}{|c|c|c|c|c|}
\hline Model & $\mathrm{EBV}_{\mathrm{a}} \pm \mathrm{SE}$ & $\mathrm{EBV}_{\mathrm{c}} \pm \mathrm{SE}$ & $\mathrm{ETBV} \pm \mathrm{SE}$ & Loss, ${ }^{3} \%$ \\
\hline \multicolumn{5}{|c|}{ Line $1(\mathrm{n}=268)$} \\
\hline 1 & $51.58 \pm 16.49$ & $1.61 \pm 0.78$ & $74.08 \pm 19.71$ & - \\
\hline 2 & $55.12 \pm 13.74$ & $0.93 \pm 0.94$ & $68.15 \pm 25.80$ & 8.00 \\
\hline 3 & $39.22 \pm 25.89$ & $1.87 \pm 0.57$ & $65.32 \pm 28.01$ & 11.83 \\
\hline 4 & $52.45 \pm 16.03$ & $1.40 \pm 0.88$ & $72.03 \pm 21.43$ & 2.77 \\
\hline \multicolumn{5}{|c|}{ Line $2(\mathrm{n}=255)$} \\
\hline 1 & $67.76 \pm 15.77$ & $1.89 \pm 0.44$ & $94.26 \pm 21.94$ & - \\
\hline 2 & $67.59 \pm 15.96$ & $1.89 \pm 0.45$ & $94.03 \pm 22.20$ & 0.24 \\
\hline 3 & $60.78 \pm 21.97$ & $1.70 \pm 0.61$ & $84.56 \pm 30.56$ & 10.30 \\
\hline 4 & $65.34 \pm 18.19$ & $1.83 \pm 0.51$ & $90.89 \pm 25.30$ & 3.58 \\
\hline
\end{tabular}

genetic SD for social effects, which would be difficult to attain.

For each of the 4 lines, Spearman rank correlations between ranks of boars were calculated using EBV from each model as a measure of how well EBV from reduced models were able to rank animals compared with model 1. Spearman rank correlations within lines were: 0.30 to $1.00,0.84$ to 0.96 , and 0.64 to 0.98 between model 1 and models 2, 3, and 4. In some lines boars selected based on reduced models were ranked much differently compared with the full model. For example, rank correlations between models 1 and 2 were $0.92,1.00,0.30$, and 0.91 for lines 1 through 4 . Selection in line 3 based on model 2 was greatly different from selection based on model 1. Rank correlation coefficients between models 1 and 3 were $0.84,0.91,0.88$, and 0.96 for lines 1 through 4. Rank correlation coefficients between models 1 and 4 were $0.98,0.96,0.64$, and 0.98 for lines 1 through 4. Average Spearman rank correlations over all lines were $0.78,0.90$, and 0.89 between model 1 and models 2,3 , and 4 .

Average total ETBV are equal to the sum of estimated direct breeding values $\left(\mathbf{E B V}_{\mathrm{a}}\right)$ and estimated social breeding values $\left(\mathbf{E B V}_{\mathbf{c}}\right.$ ) weighted by 14 (number of competitors in a pen) with models 1 and 3 . With models 2 and 4, the average ETBV are equal to $\mathrm{EBV}_{\mathrm{a}}$. Pearson product-moment correlations also were used to compare estimates of breeding values with different models. Correlations between $\mathrm{EBV}_{\mathrm{a}}$ and $\mathrm{EBV}_{\mathrm{c}}$ with model 1 were highly variable among lines: $0.41,1.00$, -0.72 , and 0.96 for lines 1 to 4 . This variation is probably due to small, but variable, estimates of heritability for social effects. Average product-moment correlations for ETBV over all lines were: 0.79, 0.91, and 0.90 between model 1 and models 2,3 , and 4 .

The potential for decreased genetic superiority with reduced models can be illustrated by selecting the top $10 \%$ of boars with rankings based on the reduced models, but with estimated breeding values calculated with model 1 (Tables 4 and 5). Average total breeding values $\left(\mathrm{ETBV}=\mathrm{EBV}_{\mathrm{a}}+14 \mathrm{EBV}_{\mathrm{c}}\right)$ for the top $10 \%$ of boars se- lected with model 1 were $74.08,94.26,31.79$, and 92.88 $\mathrm{g}$ for lines 1 through 4, respectively. For rankings based on model 2, but with EBV calculated with model 1, average total breeding values for the top $10 \%$ were 68.15 , $94.03,7.33$, and $84.72 \mathrm{~g}$. For rankings based on model 3 average total breeding values were $65.32,84.56,29.71$, and $89.91 \mathrm{~g}$, and for rankings based on model 4, average total breeding values were $72.03,90.89,19.36$, and $91.14 \mathrm{~g}$.

Averages of $\mathrm{EBV}_{\mathrm{c}}$ for the top $10 \%$ of boars selected with model 1 were 1.61, 1.89, 1.72, and $4.04 \mathrm{~g}$ for lines 1 through 4, respectively. Empirical estimates of correlated responses for genetic social effects from selection for direct genetic effects with model 2 for boars ranked in the top $10 \%$ were $0.93,1.89,-2.19$, and 3.52 $\mathrm{g}$ for lines 1 through 4 . For rankings based on model 3, average social breeding values calculated with model 1 were $1.87,1.70,1.72$, and $4.00 \mathrm{~g}$ for lines 1 through 4 . For rankings based on model 4 , average social breeding values were $1.40,1.83,-0.93$, and $3.94 \mathrm{~g}$ for lines 1 through 4 , respectively.

The decreases in averages of estimated total genetic superiority due to ignoring genetic social effects for selecting the top $10 \%$ of boars were 8.00, 0.24, 76.94, and $8.79 \%$ with ranking based on model 2 compared with model 1 for lines 1 through 4 . With estimates of heritability for genetic social effects close to zero, in the case of line 2, ignoring genetic social effects in the selection index did not change estimates of total genetic gains much compared with model 1 . The decreases in estimated total genetic superiority due to ignoring social permanent environmental effects for selecting the top $10 \%$ of boars were $11.8,10.3,6.5$, and $3.2 \%$ with ranking based on model 3 compared with model 1 for lines 1 through 4 . With model 4 (both genetic and permanent environmental social effects ignored), the relatively large proportional decrease in genetic superiority was $39.1 \%$ in line 3 , which had a negative $\sigma_{a c}$. The average decreases in estimated total genetic superiority over all lines were $23.59,8.0$, and $11.8 \%$ for models 2,3 , and 4 , respectively, compared with model 1 . 
Table 5. Average estimates of direct genetic, competition genetic, and total breeding values $(\mathrm{ETBV})^{1}$ for $\mathrm{ADG}(\mathrm{g})^{2}$ for the top $10 \%$ of boars ranked based on each model, but EBV calculated with model 1 for 2 sire lines

\begin{tabular}{|c|c|c|c|c|}
\hline Model & $\mathrm{EBV}_{\mathrm{a}} \pm \mathrm{SE}$ & $\mathrm{EBV}_{\mathrm{c}} \pm \mathrm{SE}$ & $\mathrm{ETBV} \pm \mathrm{SE}$ & Loss, ${ }^{3} \%$ \\
\hline \multicolumn{5}{|c|}{ Line $3(\mathrm{n}=273)$} \\
\hline 1 & $7.78 \pm 18.47$ & $1.72 \pm 1.50$ & $31.79 \pm 9.95$ & - \\
\hline 2 & $38.05 \pm 10.62$ & $-2.19 \pm 1.43$ & $7.33 \pm 14.54$ & 76.94 \\
\hline 3 & $5.63 \pm 16.49$ & $1.72 \pm 1.40$ & $29.71 \pm 11.56$ & 6.54 \\
\hline 4 & $32.31 \pm 15.71$ & $-0.93 \pm 2.19$ & $19.36 \pm 17.39$ & 39.10 \\
\hline \multicolumn{5}{|c|}{ Line $4(\mathrm{n}=175)$} \\
\hline 1 & $36.34 \pm 9.04$ & $4.04 \pm 1.05$ & $92.88 \pm 22.67$ & - \\
\hline 2 & $35.47 \pm 9.81$ & $3.52 \pm 1.41$ & $84.72 \pm 29.19$ & 8.79 \\
\hline 3 & $33.85 \pm 11.40$ & $4.00 \pm 1.09$ & $89.91 \pm 25.90$ & 3.20 \\
\hline 4 & $35.96 \pm 9.43$ & $3.94 \pm 1.16$ & $91.14 \pm 24.62$ & 1.87 \\
\hline
\end{tabular}

Because estimates of variance components are by line, estimates of empirical responses to selection by line would also depend on sampling variation. General results across lines for calculating genetic superiorities of the top $10 \%$ of boars indicate that incorporating social effects in a selection index would improve total genetic gain even with small, but not near zero, variance of genetic social effects.

Accurate estimates of genetic parameters are needed for optimization of genetic improvement from selection. Genetic social effects may sometimes need to be included in statistical models to provide better estimates of direct genetic effects. To calculate total breeding value with a selection index, social breeding values should be weighted by number of competitors in a pen compared with a weight of 1 for direct breeding values. Empirical responses for total genetic value show that selection of animals based on models without social effects would result in reduced genetic gain when variances of genetic social effects are relatively large. Estimates of heritability for social effects were near zero for these 4 lines and these management conditions. However, total heritable variance due to both direct and social genetic effects was large, which suggests that incorporating social effects in selection indices might be important. Further study of the effects of social interactions in different environments is needed to determine situations in which effectiveness of selection for total genetic value can be improved by incorporating social effects in models and indexes.

An anonymous reviewer has suggested that this model for direct and social effects not be used in the future for several reasons. One reason is the complete confounding of fixed pen effects and environmental social effects and near confounding when pens are modeled as random effects. In this study pen effects were not included in the model. Another reason is one the authors and others have informally discussed; with many pigs in a pen, some pigs may never interact with other pigs. The authors look forward to publication of the appropriate model.

\section{LITERATURE CITED}

Arango, J., I. Misztal, S. Tsuruta, M. Culbertson, and W. Herring. 2005. Estimation of variance components including competitive effects of Large White growing gilts. J. Anim. Sci. 83:12411246.

Bergsma, R., E. Kanis, E. F. Knol, and P. Bijma. 2008. The contribution of social effects to heritable variation in finishing traits of domestic pigs (Sus scrofa). Genetics 178:1559-1570.

Bijma, P., W. M. Muir, and J. A. M. van Arendonk. 2007. Multilevel selection 1: Quantitative genetics of inheritance and response to selection. Genetics 175:277-288.

Boldman, K. G., L. A. Kriese, L. D. Van Vleck, C. P. Van Tassell, and S. D. Kachman. 1995. A manual for use of MTDFREML. A set of programs to obtain estimates of variance and covariances [Draft]. USDA-ARS, Clay Center, NE.

Cappa, E. P., and R. J. C. Cantet. 2006. Bayesian estimation of direct and competition additive (co)variance in individuals mixed models. CD-ROM Communication No. 28-06 in Proc. 8th World Congr. Genet. Appl. Livest. Prod., Belo Horizonte, MG, Brazil.

Cassady, J. P., and L. D. Van Vleck. 2004. Estimation of (co) variance components due to genetic competition effects in pigs. J. Anim. Sci. 82(Suppl. 2):38. (Abstr.)

Chen, C. Y., S. D. Kachman, R. K. Johnson, S. Newman, and L. D. Van Vleck. 2008. Estimation of genetic parameters for average daily gain using models with competition effects. J. Anim. Sci. (Accepted).

Griffing, B. 1967. Selection in reference to biological groups. I. Individual and group selection applied to populations of unordered groups. Aust. J. Biol. Sci. 10:127-139.

Henderson, C. R. 1975. Comparison of alternative sire evaluation methods. J. Anim. Sci. 41:760-770.

Muir, W. M. 2005. Incorporation of competitive effects in forest tree or animal breeding programs. Genetics 170:1247-1259.

Muir, W. M., and A. Schinckel. 2002. Incorporation of competitive effects in breeding programs to improve productivity and animal well being. Proc. 7th World Congr. Genet. Appl. Livest. Prod. CD-ROM Communication No. 14-07. Montpellier, France.

Van Vleck, L. D., and J. P. Cassady. 2004. Modification of MTDFREML to estimate variance due to genetic competition effects. J. Anim. Sci. 82(Suppl. 2):38. (Abstr.)

Van Vleck, L. D., L. V. Cundiff, and R. M. Koch. 2007. Effect of competition on gain in feedlot bulls from Hereford selection lines. J. Anim. Sci. 85:1625-1633.

Wright, A. J. 1986. Individual and group selection with competition. Theor. Appl. Genet. 72:256-263. 